\title{
CONSUMPTION AND HABITS: EVIDENCE FROM PANEL DATA*
}

\author{
Raquel Carrasco, José M. Labeaga and J. David López Salido
}

\begin{abstract}
The purpose of this paper is to test for the presence of habit formation in consumption decisions using household panel data. We apply the test proposed by Meghir and Weber (1996) to a Spanish panel data set in which households are observed for up to eight consecutive quarters. This temporal dimension is crucial, because it allows us to take into account time invariant unobserved heterogeneity across households ('fixed effects') and, therefore, to investigate whether the relationship between current and past consumption reflects habits or heterogeneity. Our results confirm the importance of accounting for fixed effects when ana lysing intertemporal consumption decisions allowing for time non separabilities.
\end{abstract}

The purpose of this paper is to test for the presence of habit formation in consumption decisions using household panel data. We use the test proposed by Meghir and Weber (1996) and estimate the within-period marginal rate of substitution (MRS) between commodities, which is robust to the presence of liquidity constraints. We use a Spanish panel data set in which households are observed for up to eight consecutive quarters. This temporal dimension is crucial, because it allows us to take into account time invariant unobserved heterogeneity across households ('fixed effects') and, therefore, to investigate whether the relationship between current and past consumption reflects habits or heterogeneity.

Over the last decade several influential papers have revealed discrepancies between the predictions of models that assume intertemporally separable preferences and the empirical evidence. Estimates of these models have generated puzzles that range from the equity premium (i.e. the consumption growth rate appears to be too smooth to justify the mean equity premium) to the excess sensitivity and the excess smoothness of consumption to permanent income shocks (Deaton, 1991).

A growing body of literature has emphasised the importance of allowing for habit formation, as a way of modelling time dependence in preferences, to improve the predictions of time-separable models. For instance, some authors have pursued this path and showed that habit persistence may partially solve the equity premium puzzle, because it smooths consumption growth over and above the smoothing implied by the life cycle-permanent income hypothesis with timeseparable preferences (Abel, 1990; Constantinides, 1990). In addition, if preferences exhibit habit formation, consumption reacts slowly to permanent income shocks, and this can in principle explain the excess sensitivity of nondurable

* This article has an Appendix available on this JournAL's website, www.res.org.uk. We are grateful to Sule Alan, Pedro Albarran, Richard Blundell, Martin Browning, Antonia Díaz, Michael Jerison, Maite Martinez Granado, three anonymous referees, and participants at the Microeconometric Seminar at University of Copenhagen, Universidad Carlos III and the 10th International Conference on Panel Data for helpful comments on this work. All remaining errors are our own. The first and the second authors acknowledge research funding from the Spanish DGES, Grant BEC200204294 C020102. 
consumption observed in the aggregate data. The notion of habit persistence has been also to address other important issues in macroeconomics and finances, such as the hump-shaped response of consumption to monetary and other shocks (Fuhrer, 2000), the relationship between savings and growth (Carroll et al. 2000), or the stock market volatility puzzle (Campbell and Cochrane, 1999).

Despite of the growing interest in studying consumption behaviour when preferences are assumed to be time non-separable, most of the empirical work has been done using aggregate data. Apart from the well-known aggregation problems derived from the use of this type of data (Attanasio and Weber, 1993; Attanasio, 1999; Blundell and Stoker, 1999), simple life-cycle considerations open an interesting research agenda for testing time non-separabilities in preferences at a microeconomic level.

The lack of empirical microeconomic evidence presumably arises from data availability: the microeconomic data sets used in most of the consumption literature so far contained either very limited information on consumption or none at all. Some recent exceptions are the papers by Meghir and Weber (1996) and Dynan (2000), which do not find evidence of habit formation in preferences at the household level, and Naik and Moore (1996) which find support for the habit formation model. Nevertheless, that evidence presents several drawbacks. Naik and Moore (1996) and Dynan (2000) use yearly information from the Panel Study of Income Dynamics (PSID), which only offers information on food consumption. Therefore, it is necessary to assume separability in preferences between food and other nondurables and, as emphasised by Attanasio and Weber (1995), all available studies of demand systems strongly reject such a hypothesis. Moreover, Dynan (2000) does not account explicitly for time invariant unobserved heterogeneity across households and, although Naik and Moore (1996) do, they perform a fixed effect estimation of a dynamic model but without accounting for the potential endogeneity of some of the explanatory variables. Meghir and Weber (1996), using quarterly data from the Consumer Expenditure Survey (CEX), find that, when other non-durable commodities are controlled for, there is no evidence of habit persistence in the demand system of food at home, transport and services. Nevertheless, although the CEX does follow households over time, it is only for four consecutive quarters, and this is not enough to control for time invariant unobserved heterogeneity across households. This could be crucial because, if correlated fixed effects do affect the preferences specification, improper treatment of unmeasured variables could give rise to a spurious relationship between future and past consumption due solely to uncontrolled heterogeneity. Therefore, previous evidence would be based on inconsistent estimates of the structural parameters of the model.

In this paper we overcome these potential problems and address the importance of accounting for time invariant unobserved heterogeneity across households when testing for the presence of habit formation in preferences. For that purpose, we use data from the Spanish Continuous Family Expenditure Survey (Encuesta Continua de Presupuestos Familiares, ECPF). The key to identify the structural parameters in the presence of fixed effects is that we can use information up to eight consecutive quarters for some households in the survey. This represents a main advantage over other data on consumption expenditures. These data set has recently been used by 
Browning and Collado (2001), who were the first to show the advantages of having a panel data set that gives information over more than four quarters. They exploit this feature of the data, together with a particular feature of the Spanish pay system, to test whether the household demand reacts to predictable changes in household income. In our context, this large data set allows us to rule out the fixed effects by a proper transformation of the empirical specification. Moreover, an adequate set of instruments can be used in the estimation, since enough lagged values of the variables are available. Given that the ECPF contains information on several consumption commodities, we model three nondurable goods: food at home, transport and services. Conditioning on labour market variables and other non-durable goods, we estimate the intertemporal Euler conditions and the within period MRS between goods, which are robust to the presence of liquidity constraints.

Our results confirm the importance of accounting for fixed effects when analysing consumption decisions allowing for time non-separabilities. When we do not account for unobserved heterogeneity, we find that preferences are intertemporally separable and the results are the same whether using MRS or Euler equations. However, our results are markedly different once we control for fixed effects and use an adequate set of instruments. In this case, we find evidence of habit formation according to the MRS for food and services, while for transport the parameter is not significant at standard levels. Using the Euler equations we also obtain evidence of habits for food, while no evidence of dynamics is found for transport and services. Notice that usually unobserved heterogeneity leads to spurious state dependence while in our case it hides true state dependence. This could be due to the fact that our fixed effects are not the usual ones, because they represent a nonlinear combination of unobserved components and observed variables.

The paper is organised as follows: Section 1 presents the theoretical model, the empirical specification, and the estimation strategy. In Section 2 we describe the data set used. Section 3 contains the estimation results. Finally, Section 4 presents some concluding remarks.

\section{The Model and the Empirical Specification}

Following Meghir and Weber (1996), we present a model in which borrowing restrictions are present. It is well known that liquidity constraints invalidate the standard Euler equations by introducing dependence on variables in the information set of the consumer. Therefore, in a model based on a single good or a composite of non-durable goods one can never be sure that such dependence in the data comes from liquidity constraints or intertemporal non-separabilities. Nevertheless, this identification problem can be solved by looking at several commodities.

We limit the study to three non-durable goods: food at home, transport and services. ${ }^{1}$ We assume that the household maximises the present discounted value of a lifetime utility

\footnotetext{
1 The reason is that these goods cannot generally be used as a means of alleviating liquidity con straints and are generally consumed by all households and hence we minimise the presence of zeros. It also allows for a closer comparison with Meghir and Weber (1996).
} 


$$
\max _{\left\{C_{t}\right\}} \mathrm{E}_{t} \sum_{k=t}^{T} \beta^{k}{ }^{t} U_{k}\left(\mathbf{C}_{k}, \mathbf{C}_{k} \quad 1, X_{k}\right),
$$

where $\mathrm{E}_{t}$ represents the expectation conditional on information at time $t, \mathbf{C}_{t}$ is a vector of goods, $\beta$ is the discount factor, and $X_{t}$ captures other family variables. The households are subject to the standard dynamic budget constraint and a function describing liquidity constraints.

From the first-order conditions of the maximisation problem (see Meghir and Weber, 1996, for details), it follows that the MRS between two goods, $j$ and $o$, in the same period, does not depend on the marginal utility of wealth and on the existence of liquidity constraints. It depends on all the quantities but only on the relative prices of the two goods, which makes it possible to identify one MRS from another. Moreover, the time dependence observed in the MRS can be understood in terms of the existence of habits or durability in consumption decisions, depending on the sign of the cross-partial derivatives $\partial U_{t+1} / \partial c_{j t}$. Habit persistence implies that $\partial U_{t+1} / \partial c_{j t}$ is negative. The intuition in the habit formation case is that households are more displeased with fluctuations in consumption than in a framework without habits and, therefore, for a given level of current consumption, larger habits lower utility. Durability has essentially the opposite effect (Ferson and Constantinides, 1991).

If liquidity constraints do not bind, it is still possible to analyse intertemporal substitution effects using the Euler equation for each good. Thus, while the MRS is robust to the presence of liquidity constraints, this is not true for the Euler equation. Therefore, the comparison between both representations of the firstorder conditions can be used to distinguish between liquidity constraints and intertemporal dependence in preferences.

In order to keep our analysis as close as possible to Meghir and Weber (1996), we assume that preferences for the three goods are described by a flexible direct translog utility function modified to allow for time non-separabilities and preference shocks:

$$
\begin{aligned}
U_{t}= & \sum_{j=1}^{3}\left(\varrho_{j t} c_{j t}+a_{j} \ln c_{j t}\right)+0.5 \sum_{j=1}^{3} \sum_{k=1}^{3} b_{j k} \ln c_{j t} \ln c_{k t} \\
& +\sum_{j=1}^{3} \gamma_{j} \ln c_{j t} \ln c_{j t} \quad 1,
\end{aligned}
$$

where $a_{j}, b_{j k}$, and $\gamma_{j}$ are coefficients to be estimated and $\varrho_{i t}$ are random parameters reflecting preference shocks. This preference specification is very flexible and allows testing several interesting hypothesis. Intertemporal separability implies that $\gamma_{j}=0, \forall j$. Homothetic separability implies $b_{j j}=0$ for all goods, and $b_{j k}=0$ for any two goods $(j, k)$ implies additive separability.

Given these preferences, the equations to be estimated take the form:

$$
\frac{1}{p_{j t}} M U_{j t}=\frac{1}{p_{o t}} M U_{o t},
$$


for the MRS between two goods $j$ and $o$ consumed at period $t$, and

$$
\frac{1}{p_{j t}} M U_{j t}=E_{t}\left[\beta \frac{\left(1+r_{t}\right)}{p_{o t+1}} M U_{o t+1}\right],
$$

for the Euler equation, where $j$ represents food and transport, the numeraire $o$ are services, $M U_{g t}$ is the marginal utility of any good $g$, $p_{g t}$ is the price of good $g$, and $r_{t}$ is the nominal interest rate between periods $t$ and $t+1$.

Finally, preferences are modelled so as to take into account demographic and labour supply variables. Hence, we consider that coefficients $a_{j}$ depend linearly on household characteristics $\left(\mathbf{z}_{t}\right)$. In our empirical specification we have included among the variables $\mathbf{z}$ the age and education of the head of the household, family composition variables and seasonal dummies. Of particular interest is the labour supply behaviour, which is expected to affect the utility derived from consumption. This happens when decisions on consumption and leisure are taken simultaneously, making them non-separable. Both, research on labour supply and the recent literature on non-durable consumption have controlled for these factors as determinants of the life-cycle shape of consumption (Browning and Meghir, 1991; Attanasio and Browning, 1995). Therefore, dummies for the labour force participation of wife and husband have been also included. Although these variables should be considered endogenous, modelling labour supply is beyond the scope of this paper. Therefore, our analysis is limited to the estimation of conditional preferences, and labour supply variables are instrumented with their lagged values. $^{2}$ Moreover, the goods we model could be non-separable from other nondurable goods, which have been also included within the variables z. As suggested by Browning and Meghir (1991), the implicit demand functions are conditional on these goods and omitting them could lead to spurious dynamics. Finally, a dummy for wife's labour market status has been interacted with these goods and the quantities of food, transport and services.

\subsection{Stochastic Terms: The Role of Unobserved Heterogeneity}

In the empirical analysis of the model we have to take into account the presence of two sources of stochastic variability. Firstly, the expectational errors, $u_{j, t+1}^{t}$, which by assumption of rational expectations are orthogonal to variables dated at time $t .^{3}$ Secondly, the existence of preference shocks, $\varrho_{j t}$.

Thus, the error term of the MRS for each household takes the following form:

$$
\varepsilon_{j t}^{M R S}=\left[\frac{\varrho_{o t}+\gamma_{o} u_{o(t+1)}^{t}}{p_{o t}}\right]-\left[\frac{\varrho_{j t}+\gamma_{j} u_{j(t+1)}^{t}}{p_{j t}}\right] .
$$

\footnotetext{
${ }^{2}$ Rigidities in the Spanish labour market make lagged participation dummies good instruments for contemporaneous ones, mainly for husbands but also for wives.

${ }^{3}$ Notice that these errors can be correlated across households, so we cannot rule out the effects of aggregate shocks. However, since we use data for a relatively long time period (1985 95), we assume that aggregate shocks possibly correlated across households are averaged out.
} 
Under absence of autocorrelation, (5) is orthogonal to information known in period $t$ and to choice variables dated at $t-1$ or earlier. Therefore, we can take choices dated $t-1$ as instruments and also demographic composition at period $t$, since it is taken as predetermined. We will refer to the estimation of these equations as estimates in 'levels'.

Nevertheless, the existence of a time invariant unobserved heterogeneity component affecting the preference specification, leads to inconsistent estimates of the equation in levels. Specifically, let us assume that preference shocks for household $h$ can be written as follows:

$$
\varrho_{g t h}=\eta_{h}+\vartheta_{g t h}, \quad g=j, o .
$$

Because choice variables in any period are correlated with the fixed effects, $\eta_{h}$, they are not valid instruments. Under the previous assumptions the error term can be rewritten as follows

$$
\varepsilon_{j t h}^{M R S}=\eta_{h}\left(\frac{1}{p_{o t}}-\frac{1}{p_{j t}}\right)+\left[\frac{\vartheta_{o t h}+\gamma_{o} u_{o(t+1) h}^{t}}{p_{o t}}\right]-\left[\frac{\vartheta_{j t h}+\gamma_{j} u_{j(t+1) h}^{t}}{p_{j t}}\right] .
$$

It is evident from the previous expression that first differencing the equation does not eliminate the fixed effects. Thus, in order to drop out the $\eta_{h}$, we define the variable $\kappa_{j t}^{M R S}=\left(1 / p_{o t}-1 / p_{j t}\right)$. Then, if one multiplies the MRS at time $t$ by $\kappa_{j t}^{M R S}$ and that at time $t-1$ by $\kappa_{j t}^{M R S}$, the difference between the two expressions yields an error term that does not depend on the fixed effects. We will refer to the estimation of this model as estimates in 'differences'. In this case, the error of the differenced equation is orthogonal to the choice variables dated $t-2$ and earlier, and we can use them as valid instruments.

Similarly, the error term of the Euler equation takes the following form:

$$
\varepsilon_{j t}^{E}=\left[\beta \frac{\varrho_{o(t+1)}\left(1+r_{t}\right)}{p_{o(t+1)}}-\frac{\varrho_{j t}}{p_{j t}}\right]+u_{o(t+1)}^{t}+u_{o(t+2)}^{t}-u_{j(t+1)}^{t} .
$$

As in the case of the MRS, in the absence of fixed effects the error term is orthogonal to information known in period $t$ and to choice variables dated at $t-1$ and earlier. In order to account for the presence of fixed effects we proceed along the lines suggested for the MRS. In particular, we quasi difference away the fixed effects by using the variable $\kappa_{j t}^{E}=\left[\beta\left(1+r_{t}\right) / p_{o t+1}-1 / p_{j t}\right]$. Therefore, choice variables dated at $t-2$ and earlier can be used as instruments in order to obtain consistent estimates of the structural parameters. Notice that, as services related variables are dated at $t+1$, more instruments are available for the Euler equations than for the MRS, for which all variables are dated at $t$. Nevertheless, the same set of instruments has been used in both cases. ${ }^{4}$

\footnotetext{
${ }^{4}$ In order to estimate both the MRS and the intertemporal Euler conditions using the same nor malisation restrictions on the coefficients, we estimate Euler equations in which services are dated at $t+1$ and food and transport are dated at $t$, since we are mainly interested in Euler equations for testing. Nevertheless, other Euler equations could have been chosen (for example, food dated at $t+1$ and transport and services dated at $t$ ).
} 


\subsection{Estimation}

The two models we estimate consist of two equations each: food versus services and transport versus services. Estimation is performed using the generalised method of moments, GMM (Hansen, 1982).

For the MRS representation of the first-order conditions the error term of the equation in levels has the following form (dropping the $h$ subscript denoting households):

$$
\begin{aligned}
\varepsilon_{j t}= & \frac{1}{e_{o t}}-\frac{a_{j 0}}{e_{j t}}-\sum_{k} a_{j k}\left(\frac{z_{k t}}{e_{j t}}\right)-\sum_{s} b_{s j}\left(\frac{\ln x_{s t}}{e_{j t}}\right)+\sum_{k} a_{o k}\left(\frac{z_{k t}}{e_{o t}}\right)+\sum_{s} b_{s o}\left(\frac{\ln x_{s t}}{e_{o t}}\right) \\
& -\gamma_{j 1} \frac{\ln x_{j t} 1}{e_{j t}}-\gamma_{j 2} \frac{\ln x_{j t+1}}{e_{j t}}+\gamma_{o 1} \frac{\ln x_{o t} 1}{e_{o t}}+\gamma_{o 2} \frac{\ln x_{o t+1}}{e_{o t}}
\end{aligned}
$$

for $j$ equal to food and transport. In (9) $e_{j t}$ is the nominal expenditure on $\operatorname{good} j, x_{j t}$ is the quantity for good $j$, and $z_{k t}$ represents household composition variables and the rest of the variables included in the specification. The parameters of good ' $o$ ' (services) appear in both equations and we have imposed the normalisation restriction that $a_{o 0}=1$.

To estimate this system, we first minimise the quadratic form for $j=$ food/ services, transport/services to obtain parameter estimates with no cross-equation restrictions. We then apply minimum distance to the unrestricted coefficients to impose the cross-equation restrictions given by the theoretical model and to recover the structural parameters. First of all, we impose the equality of the parameters of the services equation across the two MRS and the two Euler equations. Secondly, symmetry is imposed. Finally, we impose equality of the parameters for the lag and lead of quantities in each equation (see (9)).

Similarly, for the Euler equation we have

$$
\begin{aligned}
\varepsilon_{j t}= & \frac{R_{t}}{e_{o t+1}}-\frac{a_{j 0}}{e_{j t}}-\sum_{k} a_{j k}\left(\frac{z_{k t}}{e_{j t}}\right)-\sum_{s} b_{s j}\left(\frac{\ln x_{s t}}{e_{j t}}\right) \\
& +\sum_{k} a_{o k}\left(\frac{z_{k t+1} R_{t}}{e_{o t+1}}\right)+\sum_{s} b_{s o}\left(\frac{\ln x_{s t+1} R_{t}}{e_{o t+1}}\right) \\
& -\gamma_{j 1} \frac{\ln x_{j t} 1}{e_{j t}}-\gamma_{j 2} \frac{\ln x_{j t+1}}{e_{j t}}+\gamma_{o 1} \frac{\ln x_{o t} R_{t}}{e_{o t+1}}+\gamma_{o 2} \frac{\ln x_{o t+2} R_{t}}{e_{o t+1}}
\end{aligned}
$$

where $R_{t}=\beta\left(1+r_{t}\right)$. Conditional on the discount factor, $\beta$, the estimation problem is linear. We do not estimate the discount factor but we tried several different values. In particular, the results we present are obtained for $\beta=0.99 .^{5}$ The equation contains the same conditioning characteristics as the MRS.

Regarding the equations in differences, we have the same type of expressions, but with the variables transformed as explained in the previous Section.

\footnotetext{
${ }^{5}$ Nevertheless, the results are robust to small changes of the discount factor $\beta$ (i.e. 0.995 or 0.997 ).
} 


\section{The Data}

To implement the model we use eleven years (1985-95) of a Spanish data set, the Continuous Family Expenditure Survey. The ECPF is a rotating panel based on a survey conducted by the Spanish National Statistics Office (Instituto Nacional de Estadística, INE). The ECPF reports interviews for about 3,200 households every quarter randomly rotating at $12.5 \%$ each quarter. As a result, we can follow a household for a maximum of eight consecutive quarters.

This survey has important advantages over other data sets which have consumption information. The available data sets for the US (the CEX and the PSID) and the UK (Family Expenditure Survey, FES) report information on consumption, income, demographic characteristics and other variables. Nevertheless, in the FES each household is interviewed only once (Attanasio and Weber, 1993; Attanasio and Browning, 1995) and the PSID only reports information on food consumption and, therefore, it makes impossible to control for the presence of other goods which may well be non-separable from food. By contrast, in the CEX each household is interviewed five quarters, although only four are available (see Bureau of Labour Statistics, Handbook of Methods, for additional details). The ECPF shares with the CEX some structural characteristics, and differs crucially in others. The fact that it is a longer panel represents the main advantage over the CEX. It allows us to transform the model to rule out fixed effects and to use an adequate set of instruments to obtain consistent estimates of the parameters.

We have 125,394 observations in the original data set. In Table 1 we present the structure of the data in terms of the number of interviews completed by the households. We should note that there is some evidence of attrition in the sample, although during this period a relatively large number of households complete eight consecutive interviews. Since our results could be affected by attrition bias, we use the unbalanced panel in the estimation process.

We select households reporting full information for at least 5 consecutive quarters. We then select married couples, ${ }^{6}$ with or without dependent children whose head is aged 25-60. We delete households with extremely low monetary income (<300 euros). We then exclude those households whose expenditure on

Table 1

Completed Consecutive Interviews

\begin{tabular}{lc}
\hline \hline Number of Interviews & Percentage of households \\
\hline 1 & 15.46 \\
2 & 10.86 \\
3 & 9.13 \\
4 & 10.42 \\
5 & 10.29 \\
6 & 8.65 \\
7 & 8.28 \\
8 & 26.90 \\
Total & 100.00 \\
\hline \hline
\end{tabular}

\footnotetext{
${ }^{6}$ The reason is that we are interested in capturing the effect of male and female labour market status on consumption.
} 
the goods we model is zero. ${ }^{7}$ There are 100 observations with zero expenditures in food, 522 observations with zero expenditure in services and 2,824 observations with zero expenditures in transport. ${ }^{8}$ This leaves us with 12,170 observations. Once the variables have been transformed for estimation, all lags and leads needed are taken in order to estimate the Euler equation in differences, and all the missing values generated have been dropped out, our final data set contains 2,606 observations (1,499 households). Although we have an additional time period for estimating the MRS than the Euler equations, and also for estimating the models in levels than in first differences, we use the same sample in all cases.

The goods we explicitly model are food consumed at home, transport and services. Food at home does not include alcohol expenditures. Transport includes public and private transport expenditures, including fuel and maintenance. Services include education, medical and other nondurable services expenditures. We also include, and treat as given, a group of nondurable goods composed by clothing and footwear, and nondurable housing expenses. We refer to these group of goods as 'conditioning goods'. Participation dummies, variables for number of children, education of the husband and age of the husband and the spouse, as well as housing tenure variables, town size, seasonal dummies and a time trend have been also included. Table A1 in the Appendix reports the mean and the standard deviation of the variables used in the analysis. In Figures 1 and 2 we plot consumption against the quarter of the interview, both in levels and differences. The three components show an upward trend, with some effects of the crisis in the 1990s. We can also observe their different patterns of seasonality. Table A2 presents the distribution of the three components of real consumption we model and its variation across the sample. Table A3 shows the budget shares of food, transport, services and conditioning goods expenditures as a proportion of these commodities and as a proportion of total consumption (including durables). It can be seen that our demand system accounts for almost $60 \%$ of total consumption including durables. ${ }^{9}$ Once we take account of the conditioning goods, which we do not explicitly model, it turns out to be more than $90 \%$ of the basket goods of Spanish households. There are some differences among these figures and the mean shares of the whole sample, because of our sample selection. The average

\footnotetext{
7 Given the nature of these goods, it is likely that zeros represent coding errors and not corner solutions or infrequency of purchases (except probably for transport). To minimise the number of zeros we have aggregated expenditures on services to some extent.

${ }^{8}$ In transport expenditures there are 9,894 zeros out of 125,394 observations. This represents $7.89 \%$ of the number of observations in the original data set. In terms of the number of households, we have 3,226 zeros out of 26,098 , which represents $12.36 \%$. In the sample selection process, we drop 2,824 out of 19,860 observations, which represent $14.22 \%$ of the observations. Transport expenditure (whether private of public) is recorded in the monitoring week and it collects petrol or public transport fares whenever the individual is observed purchasing. Households could make both expenses with infre quency due to reasons such as they do not fill in the car every week, some of them are not car owners, or households in rural areas have not access to public transport. Labeaga and López (1997a) provide evidence about these issues as well as about the representativeness of the transport data for the whole population.

9 Browning et al. (2002) present the distribution of consumption for several goods with Spanish data from the Permanent Survey of Consumption. This survey was conducted during the years 197783 and the distribution of consumption has changed a lot in recent years. Then, our figures and theirs are not directly comparable.
} 


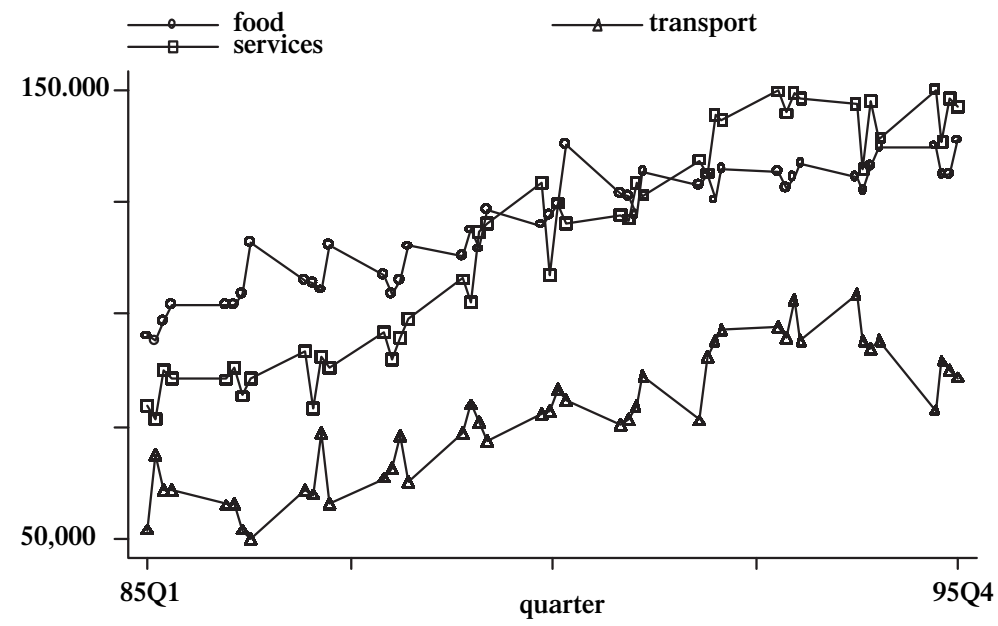

Fig. 1. Consumption Expeditures in Levels. Pesetas Per Quarter

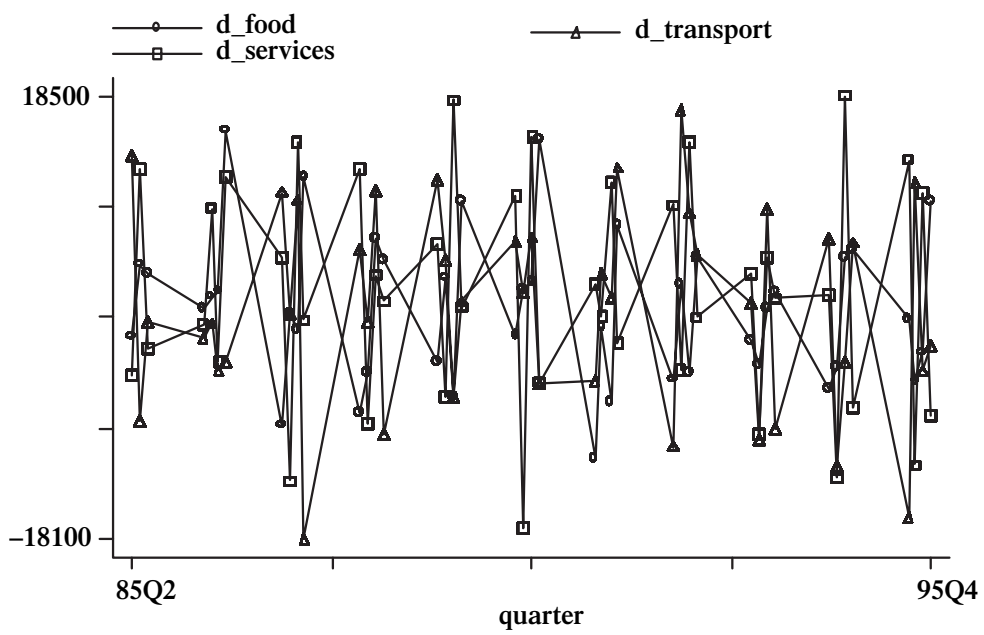

Fig. 2. Consumption Expeditures in Differences

budget share for food in the whole sample is around $31 \%$, while the shares for transport and services are smaller than those presented in the Table.

Because the intertemporal variability of the relative prices is crucial to have identification, Figure 3 shows the evolution of food and transport prices relative to services for the period considered. As can be seen, both relative prices vary over time and move differently. The correlation between them is 0.64 , so it seems possible to identify one MRS from another. 


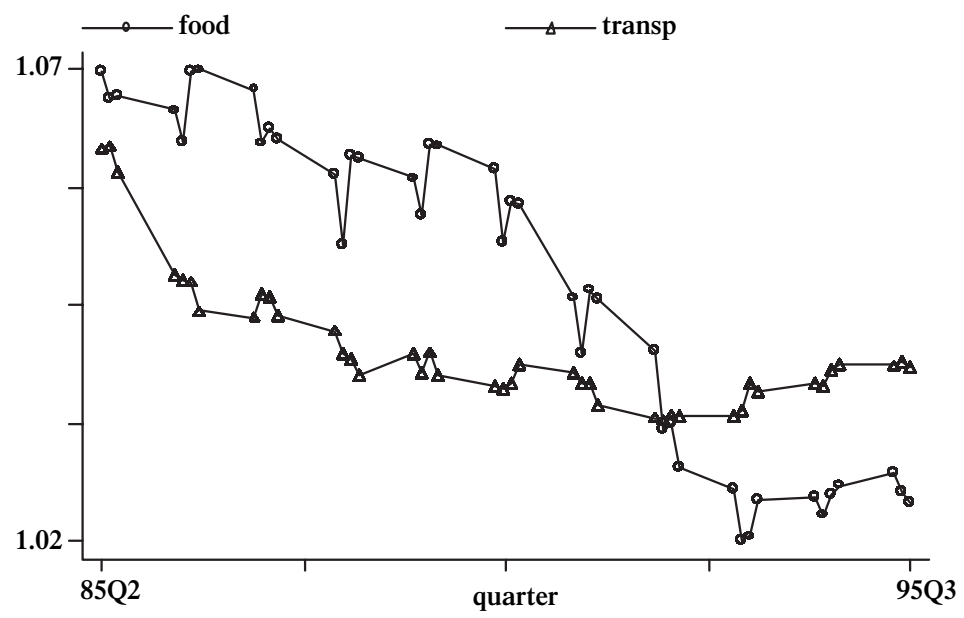

Fig. 3. Transport and food prices relative to services

Finally, in order to check the time dependence of consumption, we look at the correlation patterns exhibited by the three goods we model in the ECPF over the period 1985-95. We estimate a simple reduced form autoregressive model by OLS for the $\log$ of food, transport and services. Table 2 shows the regressions which include seasonal dummies. This yields evidence of correlation of consumption over four consecutive quarters. In what follows we try to match this autoregressive behaviour within our structural model.

\section{Results}

In this Section we report the estimates from the different models described in previous Sections. We only present the structural estimates, that is, the estimates once all within and cross equations restrictions are imposed. Two sets of estimates are presented. The first one contains the estimates of the MRS and Euler equations in levels. The second set of results examines the presence of dynamics in the MRS and Euler equations after controlling for time invariant unobserved heterogeneity. Sargan tests for instruments validity are also reported, because if correlated heterogeneity is important, the test should detect this problem in the estimation in levels. Finally, the implicit within period income and price elasticities have been also computed, as well as the intertemporal elasticity of substitution and a measure of the degree of habit formation implied by our estimates.

\subsection{Estimation in Levels}

Table A4 in the Appendix reports the results from the estimation of the MRS for food, transport and services, together with the relevant tests for 
Table 2

Autoregressive Models

\begin{tabular}{lccc}
\hline \hline & Food & Transport & Services \\
\hline Food $_{t-1}$ & $0.2122(0.018)$ & $0.0621(0.035)$ & $0.0392(0.028)$ \\
Food $_{t-2}$ & $0.1490(0.019)$ & $0.0120(0.037)$ & $0.0072(0.029)$ \\
Food $_{t-3}$ & $0.1635(0.021)$ & $0.0295(0.039)$ & $0.0324(0.031)$ \\
Food $_{t-4}$ & $0.2382(0.019)$ & $0.0399(0.037)$ & $0.0242(0.029)$ \\
Transport $_{t-1}$ & $0.0078(0.009)$ & $0.2213(0.018)$ & $0.0214(0.014)$ \\
Transport $_{t-2}$ & $0.0025(0.009)$ & $0.1622(0.018)$ & $0.0180(0.014)$ \\
Transport $_{t-3}$ & $0.0132(0.010)$ & $0.1299(0.019)$ & $0.0223(0.015)$ \\
Transport $_{t-4}$ & $0.0066(0.010)$ & $0.1922(0.019)$ & $0.0082(0.015)$ \\
Services $_{t-1}$ & $0.0016(0.013)$ & $0.0671(0.025)$ & $0.2720(0.019)$ \\
Services $_{t-2}$ & $0.0128(0.013)$ & $0.0570(0.025)$ & $0.1691(0.020)$ \\
Services $_{-3}$ & $0.0064(0.013)$ & $0.0070(0.024)$ & $0.1760(0.019)$ \\
Services $_{t-4}$ & $0.0183(0.013)$ & $0.0421(0.024)$ & $0.2162(0.019)$ \\
Number of observations & & 2,606 & \\
\hline \hline
\end{tabular}

Note. Seasonal dummies included.

overidentifying restrictions. The set of instruments used includes: dummies for education, home ownership, townsize, the number of children, age and age squared of the husband and of the spouse, seasonal dummies, a time trend, prices of all goods and the interest rate, dated at $t$. Prices and interest rate have also been included dated at $t-1,{ }^{10}$ together with labour market status of the spouses, quantities of all goods, income and some interactions of income with demographics. Most of the above are also included, divided by expenditures on food, transport and services dated at $t-1$ to match the specifications we estimate as much as possible.

The first interesting result is that the Sargan test for the validity of instruments (before imposing cross equation restrictions) is high both for the food/services and transport/services MRS. The test statistic for the food/services MRS gives a value of 110.72 , while for transport/services it is 125.75 . The $5 \%$ critical value from the chi-squared for 82 degrees of freedom is $104.14 .^{11}$ This result is consistent with the presence of correlated fixed effects, which leads to rejection of the null hypothesis of the validity of the instruments. The Euler equations (see Table A5) reproduce previous results. Nevertheless, this result could also be due to misspecification. In order to discard it, we have also computed tests for the absence of serial correlation in the residuals of the equations in levels. These tests are based on the standardised average residual autocovariances which are asymptotically $\mathrm{N}(0,1)$ variables under the null of no autocorrelation. ${ }^{12}$ The p-value for food/services MRS is 0.51, while for transport/services is 0.74. For the Euler equations the corresponding p-values are 0.52 and 0.77 . Therefore, we do not find evidence of first order serial correlation (see Table 3).

\footnotetext{
${ }^{10}$ Meghir and Weber (1996) also include prices dated at $t$ and $t \quad 1$ among the set of instruments, because they are considered exogenous.

${ }^{11}$ Throughout the paper the chosen size for all tests is $5 \%$. Although this is unusually large for microdata sets, it seems sensible here given that the sample size is not very large.

12 The assumption of no serial correlation in the disturbances in levels is essential for the consistency of the estimators (Arellano and Bond, 1991).
} 
Table 3

Test for no Serial Correlation $(\mathrm{N}(0,1))$

\begin{tabular}{lcc}
\hline \hline & MRS, Levels & Euler, Levels \\
Food/Services & 0.65 (p value: $51.5 \%)$ & 0.64 (p value: $52.0 \%)$ \\
Transport/Services & 0.33 (p value: $73.6 \%)$ & 0.28 (p value: $77.1 \%)$ \\
& MRS, Differences & Euler, Differences \\
Food/Services & 1.55 (p value: $12.0 \%)$ & 2.14 (p value: $3.2 \%)$ \\
Transport/Services & 2.43 (p value: $1.5 \%)$ & $2.04(\mathrm{p}$ value: $4.1 \%)$ \\
\hline \hline
\end{tabular}

Notwithstanding the rejection of the overidentifying restrictions indicates some potential problems, we can analyse the dynamic structure derived from the models with this preference specification. In Table 4 we present the relevant parameters of the MRS and Euler equations. We first focus on testing intertemporal separability, that is, $\gamma_{j}=0, \forall j$. The relevant parameters are those on the $\log$ of lagged and leaded consumption, $\ln c_{t}{ }_{1}$ and $\ln c_{t+1}$, where $c$ is food, transport or services, depending on the equation we are considering. There is evidence that preferences are intertemporally separable: the parameters are not significant individually, so the habit formation hypotheses would be rejected. This result still holds when we consider the Euler equation: we cannot reject the null hypothesis of intertemporal separability in preferences. The fact that the Euler equation results are compatible with the ones derived from the MRS might be viewed as supporting evidence of no liquidity constraints. At this point, it is important to note that our results do not differ from those in Meghir and Weber (1996). Using a similar estimation strategy and a similar set of instruments, they find that preferences are separable and that the dynamic structure of preferences implied by the Euler equation is the same as the one implied by the MRS.

Using the MRS equations we can also test whether additive separability is a valid assumption for the group of goods we model. That is, the hypothesis that the coefficients $b_{j k}=0$. The t-statistics for the relevant hypothesis show that the effect of transport and services on food is significant, while the effect of services on transport is not. Moreover, the hypothesis that these goods are in turn separable from the conditioning goods can not be rejected according to the t-statistics. Finally, from our results the hypothesis of homothetic separability $\left(b_{j j}=0\right)$ cannot be rejected. Nevertheless, as noted in the theoretical section, these results can be potentially biased due to spurious dependence, since individual heterogeneity has not been accounted for. This issue will be considered in next Section.

Table 4

Dynamic Structure. Estimates in levels

\begin{tabular}{lcc}
\hline \hline & MRS & Euler \\
\hline Food: $\ln c_{t-1} \quad \ln c_{t+1}$ & $0.0109(0.0173)$ & $0.0191(0.0322)$ \\
Transport: $\ln c_{t-1} \quad \ln c_{t+1}$ & $0.0010(0.0034)$ & $0.0004(0.0031)$ \\
Services: $\ln c_{t-1} \quad \ln c_{t+1}$ & $0.0068(0.0061)$ & $0.0094(0.0058)$ \\
\hline \hline
\end{tabular}




\subsection{Estimation in Differences: The Role of Unobserved Heterogeneity}

In this subsection we concentrate on the estimation of models including time invariant unobserved heterogeneity in the preference specification. Our main aim is to see whether the effects obtained previously could be in part attributed to correlated fixed effects which introduce a bias in the estimated coefficients. The set of instruments now include quantities, nominal expenditures, income and prices in period $t-2$. Notice that, because prices appear in the error term, they are not valid instruments. Therefore, in this case, prices dated at period $t$ and $t-1$ should not be included among the set of instruments, and only prices dated at period $t-2$ and earlier are still valid.

As it is well known, GMM regression might have what is known as 'weak instruments' or 'weak identification', that is, instruments that are only weakly correlated with the included endogenous variables (Staiger and Stock, 1997). If instruments are weak, then the sampling distributions of GMM statistics are nonnormal, and standard GMM point estimates, hypothesis tests and confidence intervals are unreliable. This problem is especially problematic when using differences. In order to detect weak instruments, Tables A6 and A7 show the F-statistics for a test of the hypothesis that the coefficients on the excluded instruments are zero, both for the MRS and Euler equations. The F-test yields figures that range from 2.15 to 18.38 , with a p-value of 0.00 in all cases. Therefore, it seems that weak instruments does not appear to be a relevant problem. Moreover, the partial $\mathrm{R}^{2}$ statistic obtained from regressing the endogenous right-hand side variable against the potential identifying variables is also reported. The values for this statistic indicate that there is reasonable degree of correlation between the fitted values for the endogenous variables and the actual ones.

The estimated models are presented in Tables A8 and A9. As shown in the Tables, the model is not rejected by the Sargan test: in the MRS the test statistic for food/services is 96.06 (which has a p-value of $13.7 \%$ ), which at 82 degrees of freedom the $5 \%$ critical value from the chi-squared is 104.14. For transport/services, the Sargan test in the MRS is 100.19 , which has a p-value of $8.4 \%$. These results suggest the potential importance that the control for the unobserved heterogeneity has: once it is taken into account, the model is adequately transformed and the instruments are properly selected, there is no clear evidence of misspecification. The same type of results are obtained according to the Euler equations. We have carried out some sensitivity analysis by lagging the instruments one further period (which would account, for instance, for measurement errors in consumption) but our main results do not change: the Sargan test fail to reject the overidentifying restrictions. Moreover, we have also used the same set of instruments but lagged just one period. In this case, the overidentifying restrictions are rejected: the MRS test statistic in the food/services equation is 158.25, while for the transport/services MRS is 149.75 (p-value $0 \%$ in both cases). This result is not surprising, since under the presence of fixed effects choice variables dated $t-1$ are not valid instruments. We have also performed tests for the absence of firstorder serial correlation in the differenced residuals. If the disturbances in levels 
Table 5

Dynamic Structure. Estimates in differences

\begin{tabular}{lcc}
\hline \hline & MRS & Euler \\
\hline Food: $\ln c_{t-1} \quad \ln c_{t+1}$ & $0.0108(0.0042)$ & $0.0213(0.0048)$ \\
Transport: $\ln c_{t-1} \quad \ln c_{t+1}$ & $0.0003(0.0022)$ & $0.0135(0.0096)$ \\
Services: $\ln c_{t-1} \quad \ln c_{t+1}$ & $0.0010(0.0005)$ & $0.0011(0.0010)$ \\
\hline \hline
\end{tabular}

Table 6

Diagnostics. MRS (Differences)

Test for intertemporal separability (3 d.o.f)

Test for additive separability (6 d.o.f)

Test for homothetic separability (3 d.o.f)

Separability from conditioning goods (3 d.o.f)

Significance of labour market variables (16 d.o.f)

Test for equality of the services coefficients ( 27 d.o.f)
9.62 ( $p$ value: $2.2 \%$ )

134.74 ( $\mathrm{p}$ value: $0 \%$ )

27.61 ( $\mathrm{p}$ value: $0 \%$ )

153.70 (p value: $0 \%$ )

212.97 ( $\mathrm{p}$ value: $0 \%$ )

0.0004 ( $\mathrm{p}$ value: $99 \%$ )

are not serially correlated, there should be evidence of significant first-order serial correlation in the differenced residuals. The p-value for food/services is 0.12 , while for transport/services is 0.015 . For the Euler equations the p-values are 0.032 and 0.040 (see Table 3). So there is evidence that the differenced residuals show the expected MA(1) pattern.

Regarding the hypothesis of intertemporal separability, Table 5 presents the relevant parameter estimates. They are individually significant in the MRS for food and services, confirming the existence of habit formation in these cases. These are the expected results, since although durability is theoretically possible, these two items clearly include non-durable goods, while the data show evidence of intertemporal separability for transport. We see that the behaviour of transport is more erratic in all the specifications and with all subsamples we estimate than for the rest of goods. Maybe one of the reasons why the transport equation seems not to work so well is because we do not include in the right-hand side some durable goods, like the number of vehicles, that could be non-separable from transport expenditures. ${ }^{13} \mathrm{~A}$ Wald test for the joint significance of the dynamics in the MRS equation (see Table 6) takes the value of 9.62, which should be compared to a $\chi^{2}$ with 3 degrees of freedom. The $5 \%$ critical value is 7.81. This result implies that there is evidence that preferences are non-separable over time, once we have used a rather flexible structure for them.

It is interesting to point out that the dynamic effects obtained from the Euler equations (see Table 5) also offer evidence of habit formation in food, while there is no evidence that preferences are non-separable over time for transport and services. The fact that the dynamic structure from the Euler equation is compatible

\footnotetext{
${ }^{13}$ We are aware of the fact that the lack of information on the number of vehicles can somehow affect the estimates of the transport equation parameters. Nevertheless, Labeaga and Lopez (1997a) have shown that a positive purchase on transport indicates that the household owns at least one car, but consumption of families with more than one car can contaminate the mean estimates.
} 
Table 7

Equality of the Preference Parameters from MRS and Euler (Differences)

Food, Transport and Services

4.79 (p value: $18.79 \%$ )

Food and Services

2.65 ( $\mathrm{p}$ value: $26.51 \%$ )

with the one from the MRS for food consumption does not indicate the presence of liquidity constraints for this good, as the test we present below shows.

Notice that, although one normally believes that unobserved heterogeneity may lead to spurious state dependence, what we find is the reverse: unobserved heterogeneity hides true state dependence. However, we must note that our fixed effects are not the usual ones. The stochastic term in the MRS equation is given by a nonlinear combination of an unobserved component and $\left(1 / p_{0 t}-1 / p_{j t}\right)$. In order to properly control for the whole element we have used a pseudo first differencing procedure. Note that according to Figure 1 the term within brackets is negative for almost all the period. The correlation among the consumption variables and the individual effects, together with the behaviour of prices, could justify the finding that unobserved heterogeneity hides true state dependence. In our context the coefficients of lagged and leaded consumption are statistically significant when taking account of the fixed effects while they were non-significant in the levels estimations. This also applies to the Euler equation.

Given previous results, we can compare the coefficients obtained by the MRS and the Euler equations in order to further investigate whether liquidity constraints are binding or not. If habits exist and liquidity constraints do not bind, then the same parameter estimates should be obtained from the MRS and the Euler equations. We have tested for the equality of the habits parameters across both equations. The value of the test is 4.79 (p-value 0.188 ). If the test is confined to food and services, the goods for which there is evidence of dynamics, we obtain similar results (see Table 7). ${ }^{14}$ One could think that, once labour market status is accounted for, it is hard to find evidence for liquidity constraints, since households use labour market variables as a form of alleviating them. Another potential way to examine whether liquidity constraints are important, is to look at groups which are more likely to be constrained. We thus estimate the model for those individuals younger than 40 . In this case, we cannot reject the null hypothesis of intertemporal separability: the MRS test statistic is 6.11 (p-value 0.10). On the other had, we find that non-separabilities do appear in the Euler equation: the test statistic is 15.04 ( $p$-value 0.002). Moreover, in this case we find evidence against the hypothesis of equality of the coefficients obtained by the two different sets of first order conditions: the test statistic is 12.63 which at 3 degrees of freedom has a p-value of 0.0055 . These households are at the stage of taking very important decisions (about housing, fertility, and professional career of the wife, among others) and

\footnotetext{
14 Actually, if habits exist, all parameters should be equal under the null, given that the same normalisation is used throughout. We have also performed a test for the equality of all parameters across MRS and Euler equations, and the test gives a palue of 1 .
} 
their consumption does not show the same degree of inertia. For young households, even when controlling for labour market variables, liquidity constrains are still binding. ${ }^{15}$

As regards the separability across goods, there is no evidence either of homothetic separability or additive separability. Moreover, we find evidence of within period nonseparability between food, transport, services and other expenditures (conditioning goods), both in the context of the MRS and the Euler equations. In Table 6 we present the relevant Wald test for these hypotheses. It is clear that all separability assumptions are rejected. Finally, we fail to reject the null that the common coefficients across the two MRS (parameters of the services equation) are equal, although we must notice that many coefficients in the two sets of estimates are not statistically significant.

We obtain significant effects both in the MRS and Euler representations for the effect of labour market variables. In Table 6 we present a Wald test for the joint significance of the coefficients of the MRS equations relating to labour market status. The test has 16 degrees of freedom and we can strongly reject the null. Quantitatively the effect of female labour market status is also quite large. When we do not add the labour market status variables we still obtain evidence of dynamics: the value of the test for the absence of dynamics becomes 7.30 (p-value 0.063 ) in the MRS in differences and 33.79 (p-value 0.00) in the Euler equation in differences. One could think that another reason why the labour supply variables are important, in addition to non-separabilities in preferences, is that these variables tend to overcome liquidity constraints. Nevertheless, this is not really relevant for the MRS representation because its estimation is robust to the presence of liquidity constraints. Removing labour market variables could imply a misspecification of the MRS representation. It is in the Euler representation where these variables can approximate liquidity constraints.

Finally, using the results of the estimated models in levels and differences, we have calculated the within period total expenditure and price elasticities. The elasticities obtained from the model in levels are presented in order to emphasise the inappropriateness of the values obtained. Table 8 shows that, according to the estimates in levels, the income elasticity for food is very high (almost equal

Table 8

Within Period Elasticities (MRS, Levels)

\begin{tabular}{|c|c|c|c|c|c|c|}
\hline & \multicolumn{3}{|c|}{ Price Elasticity } & \multicolumn{3}{|c|}{ Income Elasticity } \\
\hline & Food & Transport & Services & Food & Transport & Services \\
\hline Mean & 0.98 & 1.05 & 0.56 & 0.98 & 1.05 & 0.59 \\
\hline Q25 & 0.99 & 1.05 & 0.92 & 0.98 & 1.01 & 0.003 \\
\hline Q50 & 0.98 & 1.03 & 0.44 & 0.98 & 1.03 & 0.26 \\
\hline Q75 & 0.98 & 1.01 & 0.05 & 0.99 & 1.05 & 0.84 \\
\hline
\end{tabular}

Note: $\mathrm{Q} i$ is the $i$ th percentile of the elasticity distribution

\footnotetext{
15 Studies that also report evidence of liquidity constraints for the young are Attanassio and Browning (1995) and Alessie et al. (1997).
} 
Table 9

Within Period Elasticities (MRS, Differences)

\begin{tabular}{lccccccr}
\hline \hline & \multicolumn{3}{c}{ Price Elasticity } & & \multicolumn{3}{c}{ Income Elasticity } \\
\cline { 2 - 4 } & Food & Transport & Services & & Food & Transport & Services \\
\hline Mean & 0.85 & 0.78 & 0.82 & & 0.84 & 0.78 & 1.23 \\
Q25 & 1.04 & 0.91 & 0.90 & & 0.70 & 0.65 & 1.18 \\
Q50 & 0.94 & 0.82 & 0.86 & & 0.94 & 0.82 & 1.31 \\
Q75 & 0.70 & 0.65 & 0.79 & & 1.04 & 0.91 & 1.60 \\
\hline \hline
\end{tabular}

to 1) and elastic to price changes at mean values. Expenditures on services are inelastic to prices and there is no income effect for a high percentage of the sample. Table 9 shows the same type of calculations, but using the estimated coefficients for the MRS in differences. The elasticities obtained have the expected signs and size and they are comparable with some results presented in the literature of demand systems. Price and income elasticities for food consumption are clearly smaller than 1 in absolute value at almost every point of the distribution. In fact, the value for income is greater than 1 just for the $12 \%$ of the distribution, the poorest households, while the own price elasticity for food is smaller than -1 for the $8 \%$ of the households. Income elasticity for transport is smaller than 1 for the whole distribution, as expected for a good which is almost a 'necessity' for Spanish families (people take the car in Spain for carrying children to school, for going to work etc. and public transport services are very cheap as well). Price elasticities for transport denote that this good is rather inelastic for most of the sample. Income elasticities for services classify these goods as luxuries (basically only rich people spend on education or health because they are universally covered by public education and health systems), while the price elasticity is smaller than 1 at mean values and near 1 at the bottom of the distribution. ${ }^{16}$

\subsection{Intertemporal Elasticity of Substitution and Habit Formation}

In this subsection we calculate the intertemporal elasticity of substitution implicit in our preferences, as well as a measure of the degree of habit formation. We try to map our estimates of the structural parameters with these two measures emphasised in the literature on consumption dynamics.

\subsubsection{Intertemporal elasticity of substitution}

In a time separable framework, the intertemporal elasticity of substitution (IES) is well defined as the inverse of the expression $-c U_{c c} / U_{c}$, where $U_{c}$ and $U_{c c}$ are, respectively, the first and second partial derivatives of the utility function with respect to consumption, $c$. In a time-separable model the product of the IES and

\footnotetext{
16 This evidence is in line with other results obtained from the estimation of within period Marshallian demand systems using this data set (Labeaga and Lopez, 1997b). Their elasticity figures are a bit smaller than ours because here we are estimating long run values.
} 
the coefficient of relative risk aversion (RRA) equals 1 . Nevertheless, as shown by Constantinides (1990) and Boldrin, Christiano and Fisher (1997), habit formation breaks the link between the IES and the level of risk aversion, being its product below 1 . Hence, we are able to obtain an upper bound for the RRA parameter:

$$
R R A<\frac{1}{I E S}=\omega_{R R A} .
$$

Using our preferences specification given in (2), the IES can be computed for each good we model, and has the following expression:

$$
I E S_{j}=\frac{\lambda_{j t}+\varrho_{j t} c_{j t}}{\lambda_{j t}-b_{j j}},
$$

where $\lambda_{j t}=a_{j}+0.5 \sum_{k \neq j} b_{j k} \ln c_{k t}+b_{j j} \ln c_{j t}+\gamma_{j} \ln c_{j t} 1$.

In Table 10 we report the implicit estimates of the IES and the upper bound for the RRA parameter for food, transport and services, according to the estimated preference parameters from the MRS in differences and evaluated at different points of the distribution. As can be seen, the upper bound for the RRA is around 1 for food and transport, which is a value commonly used to calibrate general equilibrium models. This value is quite robust across the distribution of both goods. Nevertheless, the estimated value for services is below 1, ranging between 0.53 and 0.81 . These results show that there are important sources of heterogeneity in the measure of IES, while services tend to generate a degree of IES in line with recent empirical time series evidence this is not the case for food and transport.

\subsubsection{Strength of habits}

Because intertemporal non-separabilities in preferences create a link between current and past consumption, the degree of habit formation in behaviour can be obtained by computing the fraction of past consumption that explains current consumption.

From the first-order condition of the household's optimisation problem, one can find the value of $\ln x_{j t}$ as a function of $\ln x_{j t} 1$, being $\gamma_{j} / b_{j j}$ the parameter that links current and past consumption for each of the goods we model. From the previous MRS estimates in differences, we obtain that this parameter is equal to 0.72 for food, 0.01 for transport and 0.14 for services.

Table 10

IES and $\omega_{R R A}$

\begin{tabular}{lccccccr}
\hline \hline & \multicolumn{3}{c}{ IES } & & \multicolumn{2}{c}{$\omega_{R R A}$} \\
\cline { 2 - 3 } & Food & Transport & Services & & Food & Transport & Services \\
\hline Mean & 1.01 & 1.02 & 1.51 & & 0.99 & 0.98 & 0.66 \\
Q25 & 1.01 & 1.01 & 1.89 & & 0.99 & 0.99 & 0.53 \\
Q50 & 1.02 & 1.02 & 1.45 & & 0.98 & 0.98 & 0.69 \\
Q75 & 1.03 & 1.02 & 1.23 & & 0.97 & 0.98 & 0.81 \\
\hline \hline
\end{tabular}


The estimates for food are more or less in the range needed to explain some empirical regularities such as the 'excess smoothness' of aggregate consumption, Deaton (1987) shows that $\alpha$ must equal 0.78 , or the equity premium puzzle; Constantinides (1990) shows that $\alpha$ must be 0.80 . The estimates for transport and services are far off this range. Nevertheless, one should be cautious when making these comparisons, as it is not clear that the habit formation found in the goods we model would generalise to broader measures of consumption.

\section{Conclusions}

In this paper we have shown the importance of accounting for time invariant unobserved heterogeneity across households when analysing the existence of intertemporal non-separabilities in consumption decisions. Using data from the Spanish Continuous Family Expenditure Survey, we have four main findings. First, when time invariant unobserved heterogeneity across households is not taken into account, we find evidence that preferences are intertemporally separable. This result is obtained both from the MRS and Euler equations. Moreover, the large Sargan tests of overidentifying restrictions shows evidence of misspecification. Second, once fixed effects are controlled for, the results yield evidence of habit formation for food consumption and services. In this case, the Sargan test does not detect significant correlation between the instruments and the error terms, and preferences are found to be nonseparable even when conditioning on labour market status of both spouses and other nondurable goods. Therefore, only when controlling for fixed effects do we obtain significance for the parameters reflecting habits. This could be probably due to the fact that the unobserved component of our model is not the usual one, but it is affected by prices of the commodities we model. Third, the results obtained using the intertemporal Euler conditions also offer evidence of dynamics for food and we cannot reject the equality of the coefficients obtained from the MRS and Euler equations. Finally, when we focus on households whose head is younger than 40 (who are more likely to be constrained), we find no dynamics in the MRS but non-separabilities do appear in the Euler equation. In this case, we find evidence against the hypothesis of equality of the coefficients obtained by the two different sets of first order conditions, and this result is consistent with the presence of liquidity constraints for the young.

These results show the importance of distinguishing between which has been called in the literature 'true' and 'spurious' state dependence (Heckman, 1991). Improper treatment of unmeasured variables could give rise to a relationship between future and past consumption due solely to uncontrolled heterogeneity. However, it might well be the case that individuals have different 'propensities' for having different consumption behaviour, independently of the level of consumption in previous periods. These propensities are what we have identified as time invariant unobserved heterogeneity in nondurable consumption, which should be controlled for in order to obtain a causal habit effect. 


\section{References}

Abel, A. B. (1990). 'Assets prices under habit formation and catching up with the Joneses', American Economic Review Papers and Proceedings, vol. 80, pp. 3842.

Alessie, R., Devereux, M. and Weber, G. (1997). 'Intertemporal consumption, durables and liquidity constraints. A cohort analysis', European Economic Review, vol. 41, pp. 3759.

Arellano, M. and Bond, S. (1991). 'Some test of specification for panel data. Monte Carlo evidence and an application to employment equations', Review of Economic Studies, vol. 58, pp. 27797.

Attanasio, O. P. (1999). 'Consumption', in (J. Taylor and M. Woodford, eds.) The Handbook of Macro economics, Ch. 11, Amsterdam: North Holland.

Attanasio, O. P. and Browning, M. (1995). 'Consumption over the life cycle and over the business cycle', American Economic Review, vol. 85, pp. 111837.

Attanasio, O. P. and Weber, G. (1993). 'Consumption growth, the interest rate and aggregation', Review of Economic Studies, vol. 60, pp. 63149.

Attanasio, O. P. and Weber, G. (1995). 'Is consumption growth consistent with intertemporal optimi zation? Evidence from the consumer expenditure survey', Journal of Political Economy, vol. 103, pp. 112157.

Blundell, R. and Stoker, T. (1999). 'Consumption and the timing of income risk', European Economic Review, vol. 43 (3), pp. 475507.

Bureau of Labour Statistics. Handbook of Methods, Ch. 16, (http://www.bls.gov/cex).

Boldrin, M., Christiano, L. and Fisher, J. (1997). 'Habit persistence and asset returns in an exchange economy', Macroeconomic Dynamics, vol. 1 (2), pp. 31232.

Browning, M. and Collado, M. D. (2001). 'The response of expenditures to anticipated income changes. panel data estimates', American Economic Review, vol. 91, pp. 68192.

Browning, M. and Meghir, C. (1991). 'Testing for separability of commodity demands from male and female labor supply', Econometrica, vol. 59, pp. 92552.

Browning, M., Crossley, T. F. and Weber, G. (2002). 'Asking consumption questions in general purpose surveys', CAM Working Paper 200205.

Campbell, J. Y. and Cochrane, J. (1999). 'By force of habit. A consumption based explanation of aggregate stock market behavior', Journal of Political Economy, vol. 107 (2), pp. 20551.

Carroll, C., Overland, J. and Weil, D. (2000). 'Saving and growth with habit formation', American Economic Review, vol. 90 (3), pp. 34155.

Constantinides, G. M. (1990). 'Habit formation. A resolution of the equity premium puzzle', Journal of Political Economy, vol. 98, pp. 51943.

Cuenca, J. A. (1994). 'Variables para el estudio del sector monetario', Bank of Spain Working Paper 9416.

Deaton, A. (1987). 'Life cycle models of consumption. Is the evidence consistent with the theory', in (T. Bewley, ed.) Advances in Econometrics, New York: Cambridge University Press.

Deaton, A. (1991). 'Saving and liquidity constraints', Econometrica, vol. 59 (5), pp. 1121248.

Dynan, K. (2000). 'Habit formation in consumer preferences. Evidence from panel data', American Economic Review, vol. 90, pp. 391406.

Ferson, W. and Constantinides, G. (1991). 'Habit persistence and durability in aggregate consumption', Journal of Financial Economics, vol. 29, pp. 199240.

Fuhrer, J. (2000). 'Habit formation in consumption and its implications for monetary policy', American Economic Review, vol. 90, pp. 36790.

Hansen, L. P. (1982). 'Large sample properties of generalized method of moments', Econometrica, vol. 50, pp. 102954. 
Heckman, J. (1991). 'Indentifying the hand of past. Distinguishing state dependence from hetero geneity', American Economic Review Papers and Proceedings, vol. 81, pp. 759.

Labeaga, J. M. and López, A. (1997a). 'A study on petrol consumption using Spanish panel data', Applied Economics, vol. 29, pp. 795802.

Labeaga, J. M. and López, A. (1997b). 'Flexible demand system estimation and the revenue and welfare effects of the 1995 VAT reform', Revista Espanola de Economia, vol. 13, pp. 18197.

Meghir, C. and Weber, G. (1996). 'Intertemporal non separability or borrowing restrictions? A disag gregate analysis using a US consumption panel', Econometrica, vol. 64 (5), pp. 115182.

Naik, N. Y. and Moore, M. J. (1996). 'Habit formation and Intertemporal substitution in individual food consumption', Review of Economics and Statistics, vol. 78 (2), pp. 3218.

Staiger, D. and Stock, J. H. (1997). 'Instrumental variables regression with weak instruments', Econo metrica, vol. 65 (3), pp. 55786. 